entirely aërated rather than to its want of mineral contents. Ife thinks aëration very important.

DR. H. G. BEYER agreed that aëration has a great deal to do with it, but he declared that, strange to say, the modern idea seems to be that these air injectors which were in use formerly, have been entirely eliminated. Some say they are dangerous; they want them eliminated because they introduce millions of germs and other things, which make a filter necessary, and which it is the modern aim to do away with. Another reason for doing away with the aërator is that the water may be depended on to aërate itself, and this is actually the case. Unless the filter is carefully watched it will become a source of infection rather than a means of the prevention of infection. Dr. Beyer said that the water aërator and cooler which he mentioned is a very excellent device for small ships in which the tank capacity is not sufficient to keep the water long enough in the tanks to cool it after being distilled, and if the distilled product is properly protected from impurities by strainers, a distilled water can be produced that is free from dust. The fact remains, however, that the water ought to be aerrated to make it palatable.

DR. M. L. Price, Baltimore, referred to aëration by sterilized air. There is a surgical instrument used to sterilize air, which seems to be very practicable, and he wondered if it could be used to sterilize air for aëration of water.

Dr. L. M. Powers, Los Angeles, Cal., referred to a milk evaporating plant in which the air is forced through a pipe into the vat and trays of cotton batting are placed in the stack so that the air has to pass through the cotton and is thereby filtered. Dr. Powers knew of a fish commissioner who used an atomizer so as to mix air with the water to a great advantage. He thought that a method could be devised for sterilizing the air before using it to aerrate the water and thereby supply the necessary oxygen without infection.

'Dr. H. G. BeYER said that the object of admitting the air into milk during the process of evaporation is more to facilitate evaporation than to aërate it. In distilling water, if air is allowed to pass through the water while it is evaporating in the distiller twice the amount can be produced, and a similar result follows aëration of milk.

\section{PSYCHOSIS OF MORPHINISM.*}

\section{T. D. CROTHERS, M.D.}

Superintendent Walnut Lodge Hospital.

IIARTFORD, CONN.

All writers have mentioned the general defective conception of truth and the relation of right and wrong which appears to be a prominent symptom in all persons who use morphia. It is difficult to understand whether this is a veritable paralysis of the higher reasoning centers or a defect of the senses by which distorted conceptions of facts are not recognized. In all probability both conditions exist, and what is termed moral paralysis is a symptom of some condition of degeneration which is common to these persons in the later stages. This symptom practically describes a defect in the reasoning faculties and inability to recognize the value of truth and honesty, also a disposition to conceal the facts and distort them, no matter what their relation may be.

I shall attempt to group some of these symptoms which may be termed the psychosis of morphinism. The first is a palsy of the consciousness of right and wrong and the inability or indisposition to discriminate between the real and the false. The second is an intense anxiety and zeal to explain and to give reasons for a certain conduct and an explanation of why this or that was done. Third, there is noted some local irritation and disorder of the language centers in which thought

* Read in the Section on Nerrous and Mental Diseases of the Amerlcan Medical Association, at the Fifty-sixth Annual Session, Jily, 1905. is expressed in the most extravagant and impulsive way; or in the most secretive, hesitating and doubtful words. A fourth psychosis is a morbid impulse to deceive, to take advantage, or a keen delight in swindling, misrepresenting, and acting out new characters while under the influence of morphia. This condition was first described by me some years ago, and has been confirmed in some marked criminal cases since then.

The first grouping, called moral palsies, is an impulse to live under a mask for the purpose of concealing their exact condition, or taking advantage of circumstances that appear to be favorable to some personal interest. Many of these persons show this paralysis only in connection with the use of the drug. On all other matters they are frank, honest and exceptionally truthful, but in regard to the use of opium and its alkaloids they practice the worst kind of deception and unreasoning prevarication. They often show extraordinary childishness in denying the use of the drug and manifest indignation on being suspected. Sometimes this denial is followed by intense zeal and anxiety to explain the conduct and motives. In many instances great ingenuity will be apparent to trace it to some particular cause, generally to objective things. This I call the second symptom.

In the first the drug taker is pleased stoutly to deny the implication that he is using drugs. In the second his denials are less emphatic, but his explanations of motives and conduct are so faulty and strained as to convict himself. Often these explanations refer to acts that are associated with the use of opium and not with matters outside. Some patients will be scrupulously honest and exact on matters of observation and in opinions concerning the surroundings, but in securing and using opium they are falsifiers of the boldest class.

There seems to be in many instances a growth and an increase of this particular psychosis, which begins first with mild denials of the use of the drug, then going on to shrewd explanations and reasons, and finally culminating in profound deception and general demoralization on every topic and subject relating to themselves and environment. Generally, long before this stage is reached, changes of appearance, eccentric conduct and indifference to the opinions of others with general degeneration become prominent. The stage of profuse explanation is sometimes very childish and lacking in skill to conceal the real condition. In others it is bold and ingenions, with unusual cunning and apparent frankness. Running through this is a vein of intense egotism and pleasure to convince others of great honesty and an apparent good judgment and sagacity to diseriminate as to the value of certain impressions. Thus. in one case, a concealed morphin taker, who tetected the slightest suspicion in other persons concerning his conduct, would drop everything and take infinite pains and care to disarm this suspicion.

A clergrman. who had reached this stage of morphinism that attracted attention, spent a large part of his time in cxplaining to his friends that he was innocent and was misjudged. Each new explanation, by its intensity and minuteness, failed in a degree and requires other efforts and explanation. This man was able to go on with his professional work in the pulpit without comment, but eventually resigned and disanpeared. Often this stage is associated with a general failure of vigor and previous mentality. He is duller, sleeps in the davtime, is awake at night, blunders in business affairs, makes mistakes in correspondence, forgets proper names 
and neglects to pay bills, together with the great variety of marked psychical changes. In business he may be more acute and accurate in collecting bills and contracting debts, or the opposite. A certain irregularity of thought and conduct and a suspicion of others are all typical of his condition.

In a third psychosis, marked from the beginning or only seen in the later stages, is paralysis of the language centers. The manner of expression is changed. Whether loquacious or taciturn, the words that are used to express the thoughts are strange and unusual Often they consist of expletives and forcible exclamations, low figures of speech or low slang words uttered in a wreckless way, or the opposite, viz., formal, precise, symbolic expressions that seem rather to conceal than express the feelings of the author. This psychosis is frequently seen in literature, particularly in the variable styles noted in a single article or book, suggesting at once the influence of morphia on the language centers.

A slangy, dogmatic, jerking expression followed by a stiff, pedantic style indicates two stages of morphinism. At the beginning the effects of the drug obscures the consciousness of the value of language and the meaning of the terms used. Later when this wears off, conservatism and secretiveness come on, and the language changes; misty, high-sounding words are used to express the feelings. A great variety of peculiarities in speaking and writing and the sudden change of topics, with apparent inability to keep the mind concentrated on one subject, is very significant of this form of addiction.

DeQuincy had language exaltation, or delirium, but when under the influence of opium he was able to write good English, and careful students of his writings will discover lapses and changes which are clearly due to this cause. One author has described these as defects of consciousness. Another has called them disorders of the sensation, such as hyperesthesia or anesthesia.

There is a marked mental change associated with these symptoms. With it is noted an exaggerated egotism and confidence in the patient's ability to understand the relation of events and shape his conduct so that the real condition may be concealed. In some instances the secret use of morphia exalts some of the senses and depresses others. This may account for some of the confusion states which follow. Probably taste, touch and smell are more or less affected, and the impressions from these disordered senses have much to do in perverting the reason and lowering the consciousness. In the latter stages these conditions are apparent.

A fourth psychosis may be practically called a delirium and morbid impulse to deceive, to take advantage of others, acting out a new character, enjoying the pleasure of taking advantage of others' credulity and the ability to conceal and misrepresent.

It has been noted for a long time that kleptomania was so common that many chronic cases were unable to resist the opportunity to take things. In the police courts it has been noted that some of the shrewdest swindlers, pickpockets and confidence men are addicted to the use of morphia. Under the influence of morphia they exhibit an acuteness of intellect and audacity never seen in the ordinary law breaker, but when the morphia is withdrawn they display the greatest weakness-and childishness of manner and conduct.

An example of this kind was that of a man very highly educated and of good social standing who became addicted to the use of morphia and entered on a career of swindling and deception. It seemed to be his greatest delight to go about following the crowds at watering places, hotels and the steamers, making the acquaintances of strangers and securing loans on fraudulent checks, brass jewelry and false diamonds. He had no confederates and never mingled with anybody of the same class. To his friends he represented that he was in the brokerage business, making and placing loans. He used morphia constantly, and after long journeys would return home and remain concealed for days. He carried with him various disguises and changes of clothing, and had a number of cheap crystals set in elegant rings and pins. These he would leave as security for loans made him by strangers. He had numerous letters of introduction and bill heads of prominent firms which he used on all occasions to raise money. His manner was that of great frankness and honesty, and his evident earnestness made friends wherever he went. At times he would solicit loans, giving worthless checks and references or watches and jewelry as security. Then he would pay bills for clothes, jewelry, books or board at the hotel by forged checks, receiving in return balances of money. He would call on leading business men on various plausible pretenses and secure their signatures, which he would copy so accurately on checks that the maker was unable to detect whether they were his own or forged ones. Several times he was arrested, but his great honesty and earnestness of manner completely baffled all investigation. Finally he was detected, deprived of his morphia, and the real condition discovered.

Another man of this class was a sanitarium swindler. and for many years he visited different institutions and was apparently treated for this addiction, but in every instance swindled the proprietor in fraudulent checks and loans on false securities, then disappeared. In a short time he would enter another institution, pay in advance, secure the confidence of the manager, draw back most of the money and deposit checks as securities, then have a telegraphic call to visit a dying mother. This same man traveled on the ocean steamers for two years, making many victims, assuming all sorts of disguises, but finally was arrested and convicted.

A third example was the case of a man who came under my observation charged with larceny. I found it impossible to keep him from the use of morphia. On the trial he was acquitted, but consented to remain with me. I found that he was an excellent type of the Hyde and Jekyll class while under the influence of morphia. His intelligence seemed to be of the most acute character. He reasoned quickly and accurately, was an excellent judge of human nature and adroit to take advantage of every opportunity. If accused of sinister motives, he manifested the honesty and frankness of a saint and could make his accusers regret excecdingly that thev misunderstood him. When arrested by a detective he quickly convinced him that he had made a mistake, and his injured innocence seemed so clear that the detective was overwhelmed. He left me to make a visit to a neighboring city, and soon after was arrested in the act of receiving cash for a forged note. He sent for me to confirm his statement that he could not have had such a note and that he was only a patient under my care. So shrewdly did he defend himself that the juidge relensed him.

I found that the criminal instinct to forge notes, sell gold bric-a-brac and do other most adroit pieces of swindling was a veritable delirium and one which he enjoved when under the influence of morphia. The drug gave him a certain amount of confidence in himself and marle him fearless of any results. Of course, he was a moral naralytic. The morphia rendered him more in- 
sensible to every consideration of duty of right and wrong, and he was able to judge of the weakness of others and take advantage of their circumstances in the most skillful way. He received a yearly annuity from his father's estate, was independent and not engaged in any business. His swindling operations were undertaken as a pleasure, and any gains he received from them were always used to enlarge his sphere of acquaintance and help him enjoy the pleasure of his avocation. He was a total abstainer and used morphia regularly every day, and was finally arrested, sent to state's prison and died a year later from consumption.

No doubt all such persons are moral degenerates at the beginning before the drug is taken. The use of the drug gives a certain courage and shrewdness which for the time being is an exact representation of the real condition; therefore, it is accompanied with evidence of honesty and frankness and disarms all critics. Of course, a career of crime of this class is of short duration, because the use of the drug can not be kept down to the minimum amount. The stimulating stage grows shorter and shorter and the narcotic stage longer.

One of these criminal morphinists was registered in three different hotels in a certain city. At each place he appeared in a different disguise and could so thoroughly conceal his identity and voice that he was not recognized. In each hotel he swindled the proprietor and several of the guests, and then went away without being discovered. Iater he tried the sane thing in another city, but for some reason his morphia failed to help him out and he was discovered. This psychosis is fortunately not a common one, but it exists and is recognized among detectives more frequently than elsewhere. A physician who belonged to this class for many years has done much to destroy the good will and confidence in the profession of a certain city. He was continually the storm center of slander, dishonest practices, public libels and other thoroughly disreputable acts. His death and the complete subsidence of all discontent and conflict showed that he was the cause of all the deception and intrigue.

The moral paralysis and ethical failures of morphinists show lesions and defects of the higher centers of the brain which undoubtedly may either be inherited or acquired. A stady of a number of persons suffering from this form of addiction shows that both the psychical and the physical suffer alike. We have paid great attention to the latter, but the former has received little or no study.

The gross changes seen in loss of pride and degeneration of personal appearance and sharp denials of the use of the drug are common, but the failure of the higher mentality to recognize duty and obligation to others is not studied. This contribution is along these lines. It aims merely to outline a field that is largely neglected, the study of which will enable us to apply therapeutic measures with far more exactness than ever.

A summary of what I wish to make clear may be stated as follows: The psychosis or psychical symptoms common to morphinism are, first, palsy of the consciousness of right and wrong and inability and indisposition to discriminate the ethical principles or responsibility and obligation; second, a delirious stage of profuse explanation and efforts to conceal and explain the reasons for his acts and conduct; third, a special exaltation or depression of the language centers, with a change in the manner of expression and the use of words; fourth, a veritable insanity to deceive, to misrepresent and to take artrantage of the credulity of others, not for any purposes of gain, but for the satisfaction of being able to defraud and mislead, also to act in different characters and to elude the efforts of persons who would discover the condition.

\section{DISCUSSION.}

Dr. John Punton, Kansas City, Mo., said that the psychopathic features of the morphin psychosis are factors that should be of interest to all because of the medicolegal aspects of the subject. There are two features in reference to this that makes it all the more interesting to the practitioner. One is the ethical and the other is the legal side of the question. Some time ago a man went to Dr. Punton's office and stated that he was taking three grains of morphin daily, and that as a result he thought he was losing his reasoning power. Dr. Punton asked his occupation, and the man said that he was a train dispatcher. Dr. Punton wondered whether or not the patient was a responsible man for such a position. Ethically speaking, Dr. Punton has no right to divulge secrets given him in confidence, but he asked a leading lawyer what would be the probable outcome of the case if he should divulge such a professional secret and be sued for it. The lawyer told him that lesally he would be held responsible. Only a short time since the British Medical Journal reported a similar case, and the newspapers commented on it and declared that under such circumstances the physician's duty to humanity was greater than to his patients. Soon after this patient's visit to Dr. Punton several serious accidents occurred on the railroad. and he has wondered whether the morphin did not have something to do with their occurrence.

Dr. G. R. Clark, Dearborn, Mich., asked Dr. Crothers if he had ever thought of placing those cases that were due to morphinism alongside of the cases of minor epilepsy and studying them together for six months at a time. Dr. Clark thinks that the same principles are at the bottom of each. The application of morphin in a case of epilepsy, plus the condition of the mind that always goes with that condition, would be very likely, Dr. Clark said, to create this condition of the mind.

Dr. T. D. Crotiers said that without doubt in many of these cases there is evidence of an epileptoid taint. Why the continued sedation of the sensory centers should produce exaltation of reasoning and mental activities along certain lines is a phenomenon yet to be explained. The chief of one of the large detective offices of New York City told Dr. Crothers that the most dangerous and difficult cases to detect are criminals who used morphia. He referred to an instance of a man who for over four years traveled about the central cities of the country committing the same kind of crime and eluding the sharpest detectives. One day by accident the morphia was withdrawn, when his usual shrewdness failed and he was arrested. $\mathrm{He}$ had a large circle of friends, came from a good family and was highly educated. After a prolonged study it was decided that he was insane and he was permitted to go out under the care of his friends. Within a very short time he entered on another scheme of swindling by making contracts for lightning rods. His great skill consisted in ability to disguise himself and to go back over the same section of country, repeating his swindling schemes more successfully than ever. So long as the man was using morphia regularly he succeeded. These patients develop symptoms of insanity on removal of the drug and are placed in asylums. At present their recognition before this stage is reached is exceedingly difficult, and this study calls particular attention to a new class of psychoneuropaths who are criminals in acts unknown before.

The Great Black Plague.-Tuberculosis has been designated as "the great white plague"; with equal fitness venereal infection may be termed the great black plague", since it most aptly typifies "the pestilence that walketh in darkness." It infects unseen the social body; the rast mass of disease and misery thus engendered is concealed from observation so that there exists on the part of the public the densest ignorance respecting the ravages of an infection which, working in disguise and darkness, ramifies through every rank and order of society. At the present advanced stage of preventive medicine, it may be considered a reproach to sanitary science that this large and important class of diseases is absolutely neglected by the sanitary officials.-Charities. 